\title{
Characterization of Oily and Non-Oily Natural Sediments in Palm Oil Mill Effluent
}

\author{
Reem A. Alrawi, ${ }^{1}$ Nik Norulaini Nik Ab Rahman, ${ }^{2}$ Anees Ahmad, \\ Norli Ismail, ${ }^{1}$ and A. K. Mohd Omar ${ }^{1}$ \\ ${ }^{1}$ Environmental Technology Division, School of Industrial Technology, Universiti Sains Malaysia, 11800 George Town, Malaysia \\ ${ }^{2}$ School of Distance Education, Universiti Sains Malaysia, 11800 George Town, Malaysia \\ ${ }^{3}$ Division of Analytical and Environmental Chemistry, Department of Chemistry, Aligarh Muslim University, Aligarh 202002, India
}

Correspondence should be addressed to A. K. Mohd Omar; akmomar@usm.my

Received 21 June 2012; Revised 16 October 2012; Accepted 17 October 2012

Academic Editor: Ali Nokhodchi

Copyright (C) 2013 Reem A. Alrawi et al. This is an open access article distributed under the Creative Commons Attribution License, which permits unrestricted use, distribution, and reproduction in any medium, provided the original work is properly cited.

Palm oil is one of the many vegetable oils widely consumed around the world. The production of palm oil requires voluminous amount of water with the concurrent generation of large amount of wastewater known as palm oil mill effluent (POME). POME is a mixture of water, oil, and natural sediments (solid particles and fibres).There is a dearth of information on the physical properties of these POME sediments. This study intends to distinguish the physical properties of oily and non-oily POME sediments which include sediment size, particle size distribution (PSD), sediment shape, sediment surface morphology, and sediment density. These characterizations are important for future researches because these properties have significant effects on the settling process that occurs either under natural gravity or by coagulations. It was found that the oily and non-oily POME sediments have different sizes with nonspherical irregular shapes, and because of that, the aspect ratio (AR) and circularity shape factors were adopted to describe the shapes of these sediments. The results also indicate that the density of oily POME sediment decreases as the sediment size increases.

\section{Introduction}

Raw palm oil mill effluent (POME) is a thick, brownish, highly concentrated, and colloidal slurry with $\mathrm{pH}$ ranging from 4.0 to 4.5. It contains mainly water (95-96\%), suspended solids (2-4\%), and oil (0.6-0.7\%) [1]. Freshly discharged POME has temperature between 80 and $90^{\circ} \mathrm{C}$. Palm oil production process does not utilize any chemical; hence, POME is considered as non-toxic wastewater. The chemical characterizations of POME that include biochemical oxygen demand (BOD), chemical oxygen demand (COD), total solids (TSS), oil and grease (O and G) and other chemical properties are shown in Table 1 [2].

Many studies are focused on raw POME physicochemical treatments like sedimentation by coagulation and flocculation [3], adsorption [4], electrocoagulation [5] and membrane filtration [6], and they characterized the raw POME in their studies. But there is no information about the physical properties of the suspended solids (or can be called natural sediments) that exit in the raw POME and play an important role in the separation processes like sedimentation, filtration and separation processes by the membrane. Allen (2003) mentioned that the particle settling behaviour is dependent on the particle density, particle morphology (shape, texture, etc.), size and particle size, distribution [7].

The most natural particles in industrial processes are nonspherical and irregular in shape which means it is impossible to accurately describe their sizes [8]. The size determination of the natural particles is considered a difficult task, and to overcome this, various approaches are suggested to determine their average diameter such as sieving and microscope image analysis [9]. Furthermore, there is a relationship between the average particle diameter and its shape. This can be done by multiplying the mean diameter by the shape factor to obtain the equivalent diameter $[10,11]$. Bouwman et al. [12] defined the shape factor as a number which could characterize the particle's shape, and it is derived from a microscopic image of the particle. Many different shape factors are being used in 
TABLE 1: Chemical properties of palm oil mill effluent (POME).

\begin{tabular}{lclc}
\hline Property & Range & Property & Range \\
\hline $\mathrm{pH}$ & $4.15-4.45$ & Total nitrogen & $300-410$ \\
$\mathrm{BOD}$ & $21,500-24,500$ & Suspended solid & $15,660-23,560$ \\
COD & $45,500-65,000$ & Total solid & $33,790-37,230$ \\
Oil and & $1077-7582$ & $\begin{array}{l}\text { Total volatile } \\
\text { grease }\end{array}$ & $27,300-30,150$ \\
\hline
\end{tabular}

${ }^{*}$ Unit for all parameters is $\mathrm{mg} / \mathrm{L}$ except $\mathrm{pH}$.

previous studies to describe the particles, such as Corey shape factor ( $c f s)$ [13], aspect ratio (AR) [9], circularity [9], new projection shape factor, Stokes' shape factor, and new roughness factor [12]. It was reported that the AR and circularity shape factors are suitable to describe the particle's shape in different aspects [14]. Particle aspect ratio is expressed by the ratio of the maximum diameter to minimum diameter, and the fibre aspect ratio is expressed by the ratio of mean length to the mean diameter. On the other hand, the circularity shape factor is based on the projected area of the particle and the overall perimeter $[12,15]$.

Another important property is the particle density which plays a significant role in the particle settling rate combined with the fluid density. Actually, the particle settling depends on the difference between particle and fluid densities. The volume determination of non-spherical irregular natural sediments can be done directly by either pycnometer or by a liquid or a gas sample displacement [16].

The objectives of this study were to investigate the main physical properties of oily and non-oily natural sediments in raw POME. These properties include particle size, particle size distribution (PSD), particle density, and particle surface morphology. In addition to these properties, this study examines the suitability of aspect ratio (AR) and circularity shape factors to describe the POME particles and fibres. The output of this characterization is considered as a source material for future researches because these properties play an important role and more significant impact on the separation processes like sedimentation, flocculation, filtration and separation process by membrane.

\section{Experimental}

2.1. Separation of Oily and Non-Oily Sediments from Raw $P O M E$. Raw POME was allowed to naturally settle for 24 to 48 hours to obtain POME sludge. The upper clear layer "supernatant" was drawn out by a pump, and the bottom layer "POME sludge" was taken and dewatered using fibre materials with pore openings $<20 \mu \mathrm{m}$. The dewatered POME sludge was freeze-dried completely using a freeze dryer (Model LABCONCO, USA) to get oily POME sediments.

A portion of the oily $\mathrm{POME}$ sediments was treated with n-hexane $\left(\mathrm{C}_{6} \mathrm{H}_{14}, \min 99.0 \%, \mathrm{QReC}\right)$ in a Soxhlet until all the oil has been removed to obtain non-oily POME sediments.

2.2. Particle Size and Particle Size Distribution (PSD). In this study the sieve analysis was used to estimate the particle size and PSD within a given size range. Separate batches of oily and non-oily POME particles were sieved using a sieve shaker (Model Retsch AS 200, Germany) to determine the particle size and PSD. As much as $80 \mathrm{~g}$ of the sample was placed in a weighted sieve above a series of sieves arranged with descending aperture sizes. The sieves were arranged from the top to bottom with aperture openings as follows: $1400,1000,800,500,250,125,63,45,38,20 \mu \mathrm{m}$, and the final receiving pan at the bottom. The sieves were shaken horizontally for $20 \mathrm{~min}$, followed by carefully removing each sieve for reweighing, and the weight of POME particles in each sieve was determined. The steps were repeated (2 to 5 times) until the weight of any sieve remained constant at $\pm 5 \%$ of the previous weight of the sieve [17]. The samples retained on each sieve were weighed again after the sieving process finished and were calculated by the following equation [18, 19]:

$$
\begin{aligned}
& \% \text { oversize particles } \\
& =\frac{\text { weight of retained particles on each sieve, } g}{\text { weight of total particles, } g} \\
& \quad \times 100 \% \text {. }
\end{aligned}
$$

To calculate the percentage of undersize particles, the calculation should be started with $100 \%$ of the sample and then subtract the percentage of cumulative oversize particles on each sieve as given in the following equation [19]:

$$
\begin{aligned}
& \% \text { cumulative undersize } \\
& \qquad=\% 100-\% \text { cumulative oversize. }
\end{aligned}
$$

2.3. Shape Factor. The shape factors of oily as well as nonoily POME sediments were determined using a microscopebased on image analysis. The image analysis was done by a microscope (OLYMPUS SZX9 stereo, Japan), equipped with a video camera, to determine sediment diameter size greater than $800 \mu \mathrm{m}$. For sediment size less than $800 \mu \mathrm{m}$, the compound microscope (OLYMPUS BX41, Japan) was used to determine their sizes. The software that combined with this analysis was called Analysis Image Processing "cell A."

For each size, a small amount of POME particles was spread on a clean glass slide. The agglomerated POME particles were dispersed with solvent; the oily POME particles was separated using drops of water, and the non-oily POME particles were dispersed with hexane. Five to seven individual POME particles were randomly chosen from an ensemble of particles of each sample to measure the following geometrical dimensions: minimum diameter $\left(d_{\text {min }}\right)$, maximum diameter $\left(d_{\max }\right)$, particle projected area $(A)$, and overall perimeter of the particle $(P)$ to determine two different shape factors: aspect ratio $(\mathrm{AR})$ and circularity. $\mathrm{AR}$ is determined by using the following equation [9]:

$$
\mathrm{AR}=\frac{d_{\mathrm{max}}}{d_{\min }}
$$


TABLE 2: Sieve analysis results for oily POME sediments.

\begin{tabular}{|c|c|c|c|c|}
\hline \multirow[b]{2}{*}{ Sieve size opening $(\mu \mathrm{m})$} & \multicolumn{2}{|c|}{ Sieve fractions } & \multirow[b]{2}{*}{$\begin{array}{l}\text { Cumulative \% undersize } \\
\text { (by calculation) }\end{array}$} & \multirow[b]{2}{*}{$\begin{array}{c}\text { Cumulative } \% \text { oversize } \\
\text { (by calculation) }\end{array}$} \\
\hline & $\begin{array}{l}\text { Weight of retained } \\
\text { sample }(\mathrm{g})\end{array}$ & $\begin{array}{c}\text { Mass of retained } \\
\text { sample (\% wt) }\end{array}$ & & \\
\hline 1400 & 0.000 & 0.000 & 100.000 & 0.000 \\
\hline 1000 & 0.150 & 0.188 & 99.812 & 0.188 \\
\hline 800 & 1.230 & 1.538 & 98.274 & 1.726 \\
\hline 500 & 12.930 & 16.163 & 82.111 & 17.889 \\
\hline 250 & 45.230 & 56.538 & 25.573 & 74.427 \\
\hline 125 & 19.520 & 24.400 & 1.173 & 98.827 \\
\hline 63 & 0.840 & 1.050 & 0.123 & 99.877 \\
\hline 45 & 0.000 & 0.000 & 0.000 & 100.000 \\
\hline
\end{tabular}

The circularity was measured by the following equation [9]:

$$
\text { circularity }=\frac{4 \pi A}{P^{2}} .
$$

2.4. Surface Morphology of POME Natural Sediments by Scanning Electron Microscopy (SEM). The surface morphology of both oily and non-oily POME sediments were examined by a scanning electron microscopy (SEM) (Model Leo Supra 50 VP Field Emission, Germany) combined with an Oxford INCA 400 energy dispersive X-ray (EDX or EDS). The SEM was operated at $20 \mathrm{kV}$, and the working distance was varied between 7 and $9 \mathrm{~mm}$. The POME particles were mounted on a carbon tape attached to an aluminium stab and vacuumed for 5-10 min before being inserted into the SEM system.

2.5. Determination of POME Natural Sediments Densities. POME natural sediments densities were determined from their mass and volume. The specific gravities of these sediments were calculated using the following formula [20]:

specific gravity (sp. gr.) $=\frac{\left(W_{2}-W_{1}\right)}{\left(W_{2}-W_{1}\right)-\left(W_{3}-W_{4}\right)}$,

where $W_{1}$ is the empty weight of volumetric flask (g), $W_{2}$ is the weight of volumetric flask filled with POME sediments (g), $W_{3}$ is the weight of volumetric flask filled with distilled water and POME sediments (g), and $W_{4}$ is the weight of volumetric flask filled with distilled water $(\mathrm{g})$.

The specific gravity of POME sediments was measured under room temperature $27 \pm 1^{\circ} \mathrm{C}$ by water displacement method. A $25 \mathrm{~mL}$ volumetric flask was used in place of pycnometer to measure the volume of POME sediments. Boiled distilled water was used in this experiment to keep it free from dissolved gases which might hinder the settling of the POME particles in the flask $[21,22]$. After the determination of the specific gravity of POME particles, the density can be easily calculated by using the following formula:

specific gravity $(\mathrm{sp} . \mathrm{gr})=.\frac{\text { density of the sample }\left(\mathrm{g} / \mathrm{cm}^{3}\right)}{\text { density of water }\left(\mathrm{g} / \mathrm{cm}^{3}\right)}$.
The water density depends on water temperature and atmospheric pressure. The water density at $28^{\circ} \mathrm{C}$ is $0.9955 \mathrm{~g} /$ $\mathrm{cm}^{3}$.

\section{Results and Discussion}

3.1. Particle Size and Particle Size Distribution (PSD) of POME Oily and Non-Oily Natural Sediments. This study used sieve analysis to determine the particle size and PSD of oily and non-oily natural sediments of POME separately. This analysis can provide an average particle size with particle size distribution based on this average [17]. The POME particles that passed through and were retained on each sieve gave an approximate particle size within the range of the aperture openings. It was found that the oily POME particles sizes ranged from 64 to $1000 \mu \mathrm{m}$ as shown in Table 2. No amount of particles greater than $1400 \mu \mathrm{m}$ or less than $45 \mu \mathrm{m}$ has been retained. Slightly more than $74 \%$ of the oily POME sediments are greater than $250 \mu \mathrm{m}$, and almost $100 \%$ of the oily POME sediments are greater than $63 \mu \mathrm{m}$. Hardly $2 \%$ of the sediments were larger than $800 \mu \mathrm{m}$.

The non-oily POME particles sizes ranged from 38 to $1000 \mu \mathrm{m}$ as demonstrated in Table 3. No amount of particles greater than $1400 \mu \mathrm{m}$ or less than $20 \mu \mathrm{m}$ has been retained (oversize particles). Five percent of these particles are larger than $800 \mu \mathrm{m}$ and almost $60 \%$ larger than $250 \mu \mathrm{m}$. Only about $18 \%$ of the oily particles are larger than $500 \mu \mathrm{m}$ in comparison to almost $32 \%$ of the non-oily particles.

Light microscopy was used to determine both oily and non-oily POME particles that have size less than $38 \mu \mathrm{m}$ which could not be measured by sieving process. It was found that these small particles tend to agglomerate or adhere to larger particles and produce enlarged particles greater than their actual size. This could be due to the van der waals interactive forces, chemical reaction, mechanical bonding or electrostatic charging which agrees with the observations of Adi et al. [23].

The lognormal distribution plot of the cumulative undersize percent of oily and non-oily POME particles respectively, versus sediments sizes (or sieves openings sizes) demonstrates the broad distribution of particle sizes as shown in Figures 1 and 2. 
TABLE 3: Sieve analysis results for non-oily POME sediments.

\begin{tabular}{lcccc}
\hline Sieve size opening $(\mu \mathrm{m})$ & \multicolumn{2}{c}{ Sieve fractions } & Cumulative \% undersize & $\begin{array}{c}\text { Cumulative oversize } \\
\text { (by calculation) } \\
\text { (by calculation) }\end{array}$ \\
\hline 1400 & 0.000 & $\begin{array}{c}\text { Mass of retained } \\
\text { sample (\% wt) }\end{array}$ & 0.000 & 0.000 \\
1000 & 0.540 & 0.000 & 99.325 & 0.675 \\
800 & 3.540 & 0.675 & 94.900 & 5.100 \\
500 & 21.400 & 4.425 & 68.150 & 31.850 \\
250 & 22.390 & 26.750 & 40.163 & 59.837 \\
125 & 18.420 & 27.988 & 17.138 & 82.863 \\
63 & 13.290 & 23.025 & 0.525 & 99.475 \\
45 & 0.300 & 16.613 & 0.150 & 99.850 \\
38 & 0.111 & 0.375 & 0.012 & 99.988 \\
20 & 0.000 & 0.138 & 0.000 & 100.000 \\
\hline
\end{tabular}

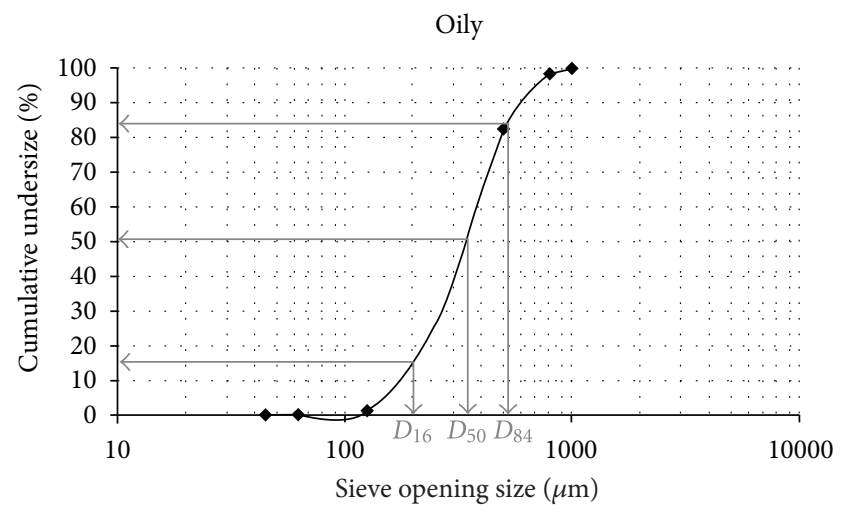

FIgURE 1: Lognormal distribution plot of cumulative undersize percentage of oily POME particles.

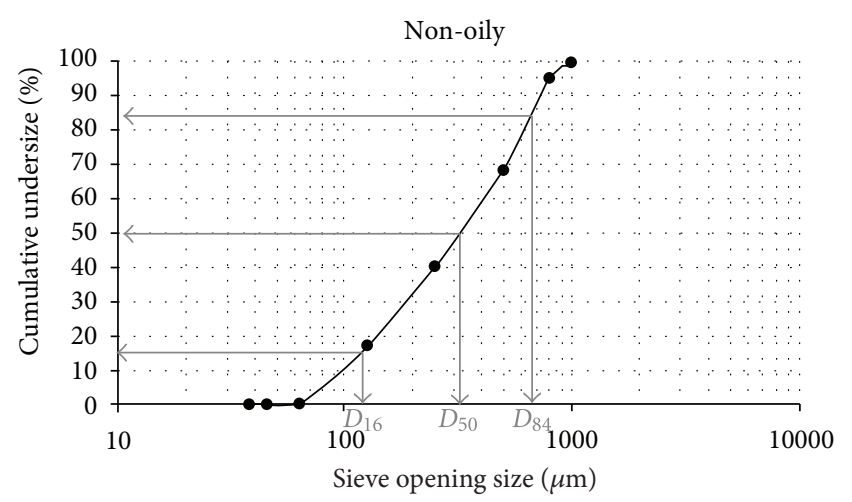

FIGURE 2: Lognormal distribution plot of cumulative undersize percentage of non-oily POME particles.

The PSD graphs provide a wide range of statistical parameters that describe both types of the POME particle size distribution using only the percentiles taken from the cumulative frequency curves. McKenna et al. mentioned in their work that two important parameters are being used to describe the lognormal distribution, namely, geometric mean diameter $\left(D_{g}\right)$ and the geometric standard deviation $\left(\sigma_{g}\right)$ [24]. The geometric mean diameter $\left(D_{g}\right)$ is obtained from $D_{16}$ and $D_{84}$. This procedure is considered standard and commonly drawn from PSD which is used even if the distribution deviates from lognormal [25]. The geometric mean diameter $\left(D_{g}\right)$ is defined as follows $[26,27]$ :

$$
D_{g}=\left(D_{84} D_{16}\right)^{0.5} \text {. }
$$

To measure the degree of sorting, geometric standard deviation $\left(\sigma_{g}\right)$ could be used and computed as follows $[26,27]$ :

$$
\sigma_{g}=\left(\frac{D_{84}}{D_{16}}\right)^{0.5}
$$

where $D_{84}$, is the diameter for which $84 \%$ of the particles are finer than $D_{84}$ and $D_{16}$ are the diameter for which $16 \%$ of the particles are finer than $D_{16}$ [26]. Birta et al. [27] mentioned in his research that (8) is used to determine the geometric standard deviation for total reign (between $D_{16}$ and $D_{84}$ ), but there are other formulas is used to determine the geometric standard deviation such as

$$
\begin{gathered}
\sigma_{g}=\frac{D_{84}}{D_{50}}, \\
\sigma_{g}=\frac{D_{50}}{D_{16}} .
\end{gathered}
$$

Equation (9) is used to determine $\sigma_{g}$ of high region (between $D_{84}$ and $D_{50}$ ) and (10) is used to determine $\sigma_{g}$ of low region (between $D_{16}$ and $D_{50}$ ) [27].

Beside these parameters, there are more statistical parameters like the median diameter $\left(D_{50}\right)$ that represented the $50 \%$ of the distribution, mode particle size, mean particle size, and particle diameters such as $D_{5}, D_{10}, D_{90}$, and $D_{95}$ at 5 th, 10th, 90th, and 95th percentiles of cumulative mass distribution, respectively. The size characteristics represented by $D_{16}, D_{50}$, and $D_{84}$ from Figures 1 and 2 combined with the statistical parameters $D_{g}$ and $\sigma_{g}$ are summarized in Table 4.

It can be seen that the size of oily POME sediments at $D_{5}$, $D_{10}$ and $D_{16}$ is bigger than that the non-oily POME sediments 
TABLE 4: The size characteristic and statistical parameters extracted from PSD graphs of oily and non-oily POME sediments.

\begin{tabular}{lcc}
\hline From graph & $\begin{array}{c}\text { Oily POME } \\
\text { sediments }\end{array}$ & $\begin{array}{c}\text { Non-oily POME } \\
\text { sediments }\end{array}$ \\
\hline$D_{5}, \mu \mathrm{m}$ & 160 & 78 \\
$D_{10}, \mu \mathrm{m}$ & 185 & 95 \\
$D_{16}, \mu \mathrm{m}$ & 200 & 120 \\
$D_{50}, \mu \mathrm{m}$ & 355 & 325 \\
$D_{84}, \mu \mathrm{m}$ & 520 & 650 \\
$D_{90}, \mu \mathrm{m}$ & 600 & 725 \\
$D_{95}, \mu \mathrm{m}$ & 710 & 800 \\
Geometric median diameter & 355 & 325 \\
$\left(D_{50}\right), \mu \mathrm{m}$ & & \\
Geometric mean diameter & 322.500 & 279.285 \\
$\left(D_{g}\right), \mu \mathrm{m}$ & & \\
Geometric standard deviation & 1.612 & 2.327 \\
$\left(\sigma_{g}\right)$ &
\end{tabular}

at the same particle size. This could be due to the agglomeration of fine oily sediments that produce flocs of large sizes. On the other hand, the geometric median diameter $\left(D_{50}\right)$ of oily POME sediments $(355 \mu \mathrm{m})$ is very much similar to the $D_{50}$ value of non-oily POME sediments $(325 \mu \mathrm{m})$, and it $\left(D_{50}\right)$ can be used to determine the settling velocity of the POME natural sediments in POME suspension. The average particle size represented by the geometric mean diameter $\left(D_{g}\right)$ can be observed from Table 4; the $D_{g}$ for oily POME particles $(322.5 \mu \mathrm{m})$ is larger than $D_{g}$ of non-oily POME particles $(279.285 \mu \mathrm{m})$.

The sorting of the sediments around the average that is represented by $\left(\sigma_{g}\right)$ shows that the oily POME sediments are moderately well sorted because they have values existing between 1.41 and 1.62. But the non-oily POME sediments have poorly sorted values because their $\left(\sigma_{g}\right)$ value lies between 2.00 and 4.00 [28].

3.2. Scanning Electron Microscopy (SEM) Examination of Oily and Non-Oily POME Sediments. SEM offers more advantages than the conventional light microscope such as greater field depth that allows more of the specimen to be focused at the same time, higher magnification so closely spaced specimens can be magnified, and clear images that provide shape and surface structure [29].

The details of the surface morphology with clear images of the oily and non-oily POME sediments can be provided by SEM and are seen in Figures 3 and 4 . The SEM images in Figures 3(a) and 3(b) show no distinction between oily and non-oily POME sediments (particles) in their surface morphology. Both POME sediments have no symmetry and are irregular in form with unequal width and breadth, thus having a wide range of sizes with odd dimensions. The particles outline comprises varying twist and turns of edges known as angular. Some of these particles are flaky, and some are clumped together and appear like one mass having a branched crystalline shape [30].
Under greater magnification (1000x), it is evident that the oily POME particles have smoother surfaces as a result of complete coating with oily layer, and all the openings are filled with oil and appear like a single mass seen in Figure 4(a). The smooth, yet uneven, surface exterior denotes that the particles are held together by the natural viscosity and thickness of the adhered oil. The vigour of this hold by the oil on the particles will affect the settling behaviour in the solution.

In comparison, the surface structure of the non-oily POME particles is more distinct, evidenced by its rugged features, rough edges, and numerous cavities as seen in Figure 4(b). Some particles have sharper edges while the majority possess more obtuse perimeter with rounder and thicker formations as opposed to flatter features belonging to other particles. Flatter POME particles appear flaky with grooves and others chunky whilst more tiny particles are loosely adhering to these surfaces.

3.3. Shapes of Oily and Non-Oily POME Sediments. The determination of oily and non-oily POME sediments shapes was done by image analysis (IA) or optical microscope based on two-dimensional images combined with special software called analysis Image Processing "cell A" used to measure the specific dimensions adopted to determine different shape factors. Although this approach is time consuming, it is considered the most efficient method that provides many details on the size and surface morphology of these sediments. Geometric determination was difficult especially for the fine oily and non-oily POME particles $(<20 \mu \mathrm{m})$ since they are bound together by particulate interactive forces in an unmethodical assemblage, forming larger particles [23].

As mentioned before, the POME particles have nonspherical and prevalently irregular shape, and rough in formation. The wide-ranging variation of the uneven forms is inherent and inadvertently formed as a result of the way the fruits were processed in the factories. The POME sediments are fundamentally residuals from the solid components of the fresh fruits and escaped parts of fresh bunches, in the form of mesocarp fibres and other fibres that passed through the processing during the extraction of palm oil.

In both POME types oily and non-oily, there are different shapes and lengths of fibres. These fibres sometimes appeared very clearly as standalone without being attached to any particle, and sometimes they were covered with particles making the fibres almost invisible. The presence of varying lengths and thicknesses of the fibre strands is visible among the oily POME particles of different sizes $\left(d_{\mathrm{O}} \leq 250 \mu \mathrm{m}, d_{\mathrm{O}} \leq\right.$ $500 \mu \mathrm{m}$, and $\left.d_{\mathrm{O}} \leq 800 \mu \mathrm{m}\right)$ shown in Figures 5(c), 5(d), and 5(e). These fibres covered with oily particles can be noticed partially or totally but at oily POME particle diameter, $d_{\mathrm{O}}>$ $1000 \mu \mathrm{m}$, fibres could not be observed because probably they were covered totally by other particles.

The larger strands have approximate diameter of $185 \mu \mathrm{m}$ and the smaller ones are about $63 \mu \mathrm{m}$ in diameter, with lengths ranging from $700 \mu \mathrm{m}$ to $7900 \mu \mathrm{m}$. No fibre strand was found in samples sieved through $63 \mu \mathrm{m}, 125 \mu \mathrm{m}$, and $1000 \mu \mathrm{m}$. The absence of fibre strands in samples sieved 


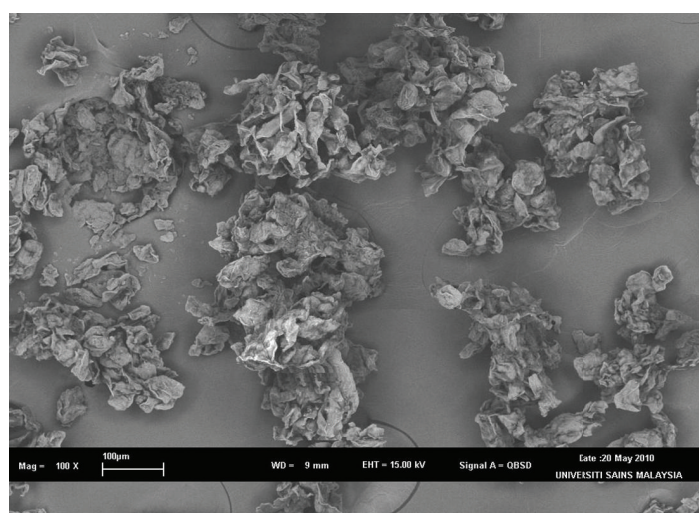

(a) Oily POME particles

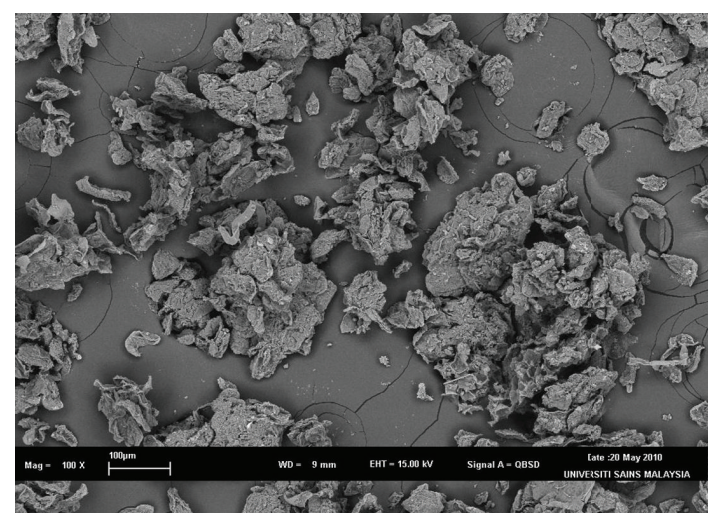

(b) Non-oily POME particles

FIGURE 3: SEM images of (a) oily and (b) non-oily POME particles at 100x magnification.

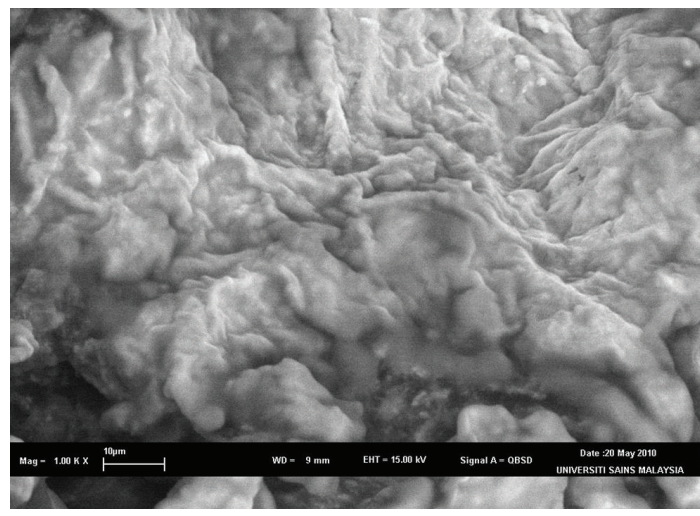

(a) Oily POME particles

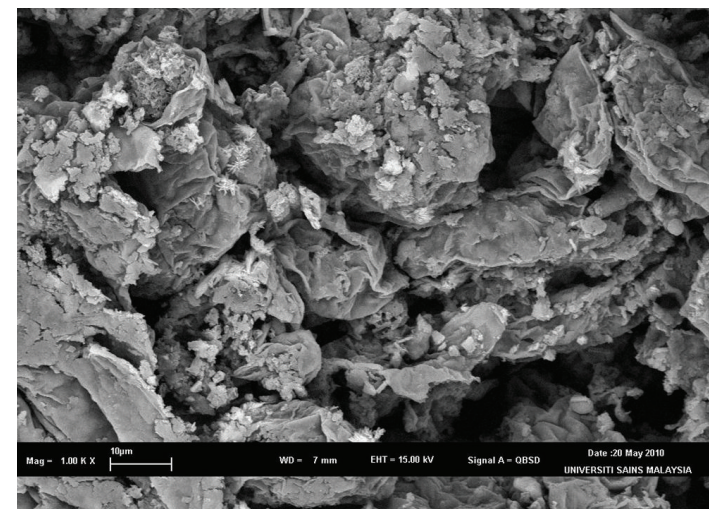

(b) Non-oily POME particles

FIGURE 4: SEM images of (a) oily and (b) non-oily POME particles at 1000x magnification.

through smaller pores might be due to the inability of the strands to make it through the holes. Most of the strands were found in samples sieved through $500 \mu \mathrm{m}$, which potentially is the reason for the obvious absence of any fibre strands in samples sieved through $1000 \mu \mathrm{m}$ openings.

Figures 6(a) to 6(i) show the range of non-oily POME particles with diameter, $d_{\mathrm{NO}}<38 \mu \mathrm{m}$ to $\leq 1000 \mu \mathrm{m}$. The particles are nonuniform in shape, width, and thickness. In the oily POME samples, fibres strands were sporadically observed among the other POME particles. On the contrary, the presences of fibres are not easy to detect among the non-oily POME particles. Thin wiry fibre-like strands can be observed in Figures 6(g) to 6(i).

POME fibres have different shapes such as simple fibre, brunched fibre, and flake fibre. The fibres present in natural sediments of POME are partially embedded in the particles or stand alone. The different shapes of oily POME fibres at different sizes covered with POME particles are shown in Figure 7. A closer look at the fibre as demonstrated in Figure 7 shows different shapes, and length of the oily POME fibres with smaller POME particles adhered to their length.

The non-oily POME fibres at different sizes and shapes are shown in Figure 8. This figure shows an equally different shapes and lengths of fibre strands found among the non-oily POME samples.

3.4. Shape Factors of Oily and Non-Oily POME Sediments. To describe the degree of divergence of non-spherical irregular POME sediments from the spherical shape, the aspect ratio (AR) and circularity shape factors were used [31].

Many studies used the average diameter, aspect ratio and circularity in their studies to characterize the particles $[12,14,32]$. Zhengmin et al. [14] used AR and circularity to compare between three brown corundum powders and found that these shape factors were suitable to describe the particle shapes in different aspects. Other studies mentioned that AR can be used when the particles have different shapes (such as fibre-like or flaky) and can provide a concept about the granules being spherical or cubical [12]. Other works used AR to determine the shape factor of minerals that have flak and fibre structure [33].

The values of AR and circularity for oily and non-oily POME particles at different range of particle sizes are shown in Table 5. From Table 5, the AR values decreased when POME particle size increased, while the circularity values increased when POME particle sizes increased. This could 


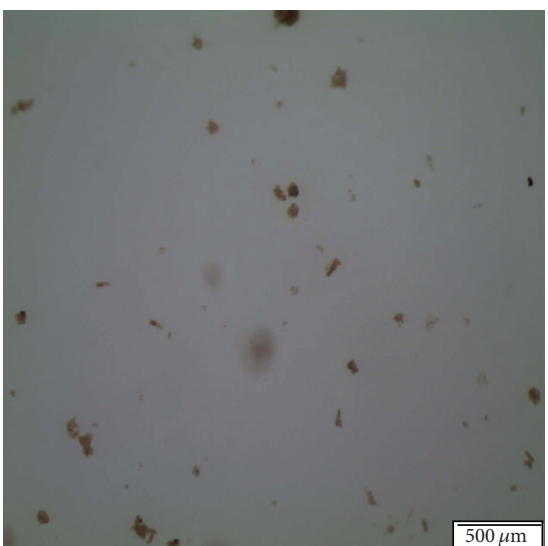

(a) $d_{\mathrm{O}}>63 \mu \mathrm{m}$

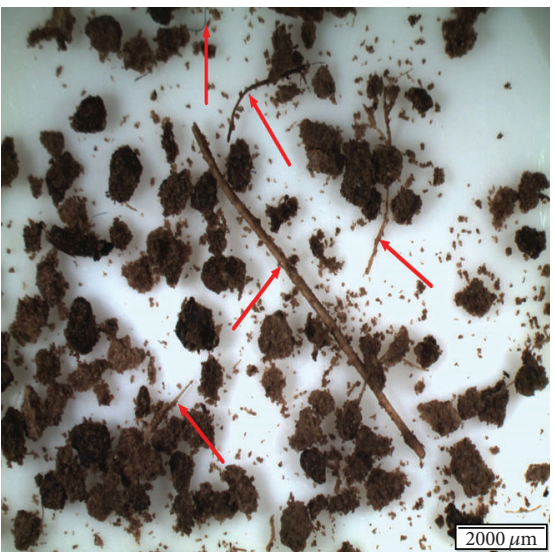

(d) $d_{\mathrm{O}}>500 \mu \mathrm{m}$

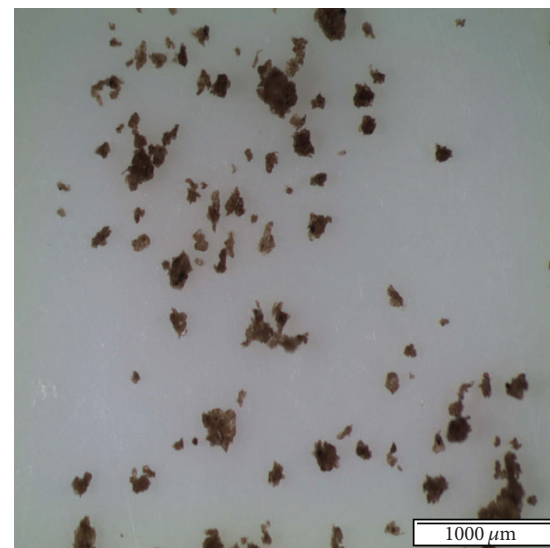

(b) $d_{\mathrm{O}}>125 \mu \mathrm{m}$

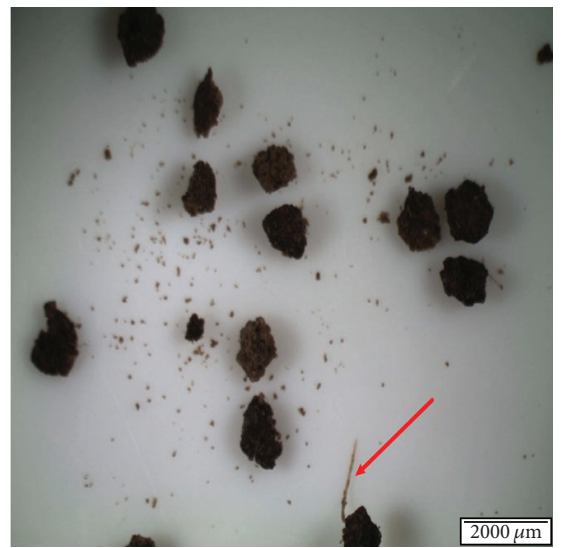

(e) $d_{\mathrm{O}}>800 \mu \mathrm{m}$

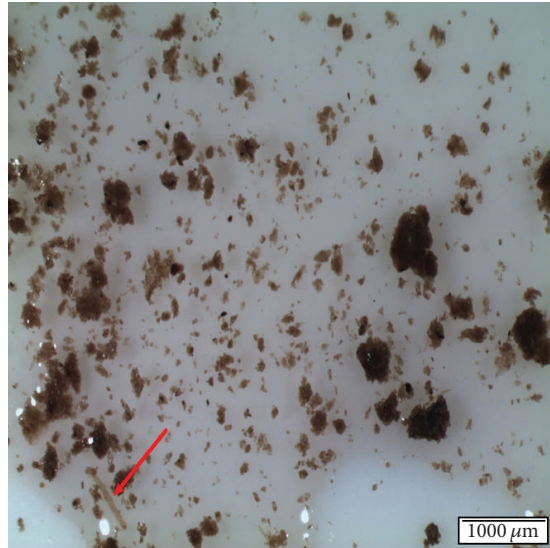

(c) $d_{\mathrm{O}}>250 \mu \mathrm{m}$

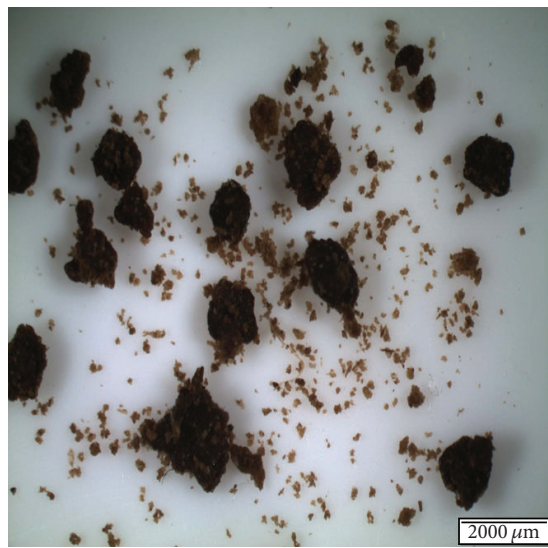

(f) $d_{\mathrm{O}}>1000 \mu \mathrm{m}$

FIGURE 5: Presence of fibres among the oily POME particles observed form sieving at different opening size.

TABLE 5: Shape factors for oily and non-oily POME sediments.

\begin{tabular}{|c|c|c|c|c|}
\hline \multirow[b]{2}{*}{$\begin{array}{l}\text { Sieve size } \\
\text { range }(\mu \mathrm{m})\end{array}$} & \multicolumn{2}{|c|}{ Oily POME sediments } & \multicolumn{2}{|c|}{ Non-oily POME sediments } \\
\hline & $\begin{array}{c}\text { Aspect } \\
\text { ratio }(\mathrm{AR})\end{array}$ & Circularity & $\begin{array}{c}\text { Aspect } \\
\text { ratio }(\mathrm{AR})\end{array}$ & Circularity \\
\hline$-45+38$ & - & - & 2.845 & 0.380 \\
\hline$-63+45$ & - & - & 2.632 & 0.403 \\
\hline$-125+63$ & 2.294 & 0.438 & 2.546 & 0.358 \\
\hline$-250+125$ & 1.729 & 0.549 & 2.062 & 0.393 \\
\hline$-500+250$ & 1.566 & 0.519 & 2.038 & 0.436 \\
\hline$-800+500$ & 1.479 & 0.479 & 1.896 & 0.445 \\
\hline$-1000+800$ & 1.397 & 0.605 & 1.692 & 0.504 \\
\hline$-1400+1000$ & 1.196 & 0.558 & 1.270 & 0.538 \\
\hline
\end{tabular}

indicate that the POME particles become closer to spherical shapes more than the elongate one when their sizes increase [32]. It is observed that the circularity of the oily POME particles was higher than the circularity of non-oily POME particle of the same size. A possible explanation for some of these results might be that the oily POME particles were covered with an oily layer making the shape of these particles smoother and more spherical than non-oily POME particles and as shown in SEM images in Figure 4(a). This finding is in agreement with Almeida-Prieto et al. (2007) who studied the relationships between 16 pellets of different shapes having diverse properties. Their study showed that AR increases with increasing sample irregularity [9]. On the contrary, Abouel-Kasem (2011) studied the effect of particle size on slurry erosion and observed that both the aspect ratio and circularity values increase with the diameter of the particles [32].

As mentioned earlier, the POME natural sediments are a mixture of particles and fibres; to determine the fibre's shape, AR was used. Table 6 presents the AR values of non-oily POME fibres.

It can be concluded from this table that the fibres that have needle-shaped or rod-shaped structure have large aspect ratios compared with other fibres that have flaky shapes.

The non-oily POME fibres have a wide range of dimensions depending on the particles elongation. In some cases although the fibre had a long diameter, it was still retained within particles having small size ranges because it had a short diameter within this particle size range; that is, the nonoily POME fibre longest length was around $4680 \mu \mathrm{m}$ but the shortest length was $100 \mu \mathrm{m}$ as shown in Table 6 , so it could 


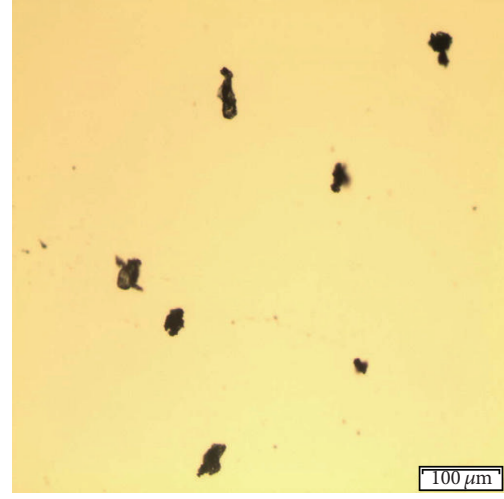

(a) $d_{\mathrm{NO}}<38 \mu \mathrm{m}$

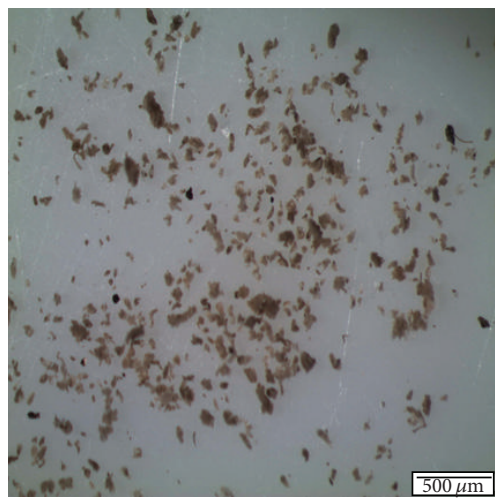

(d) $d_{\mathrm{NO}}>63 \mu \mathrm{m}$

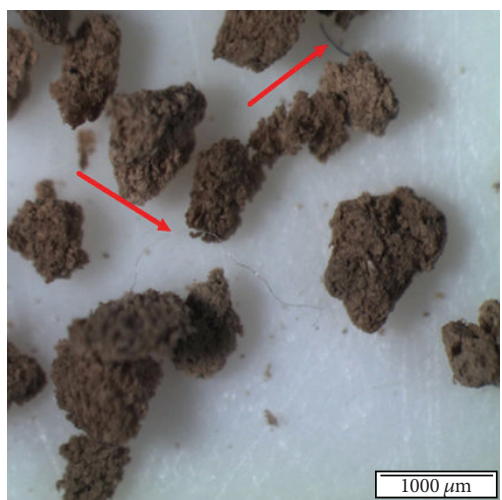

(g) $d_{\mathrm{NO}}>500 \mu \mathrm{m}$

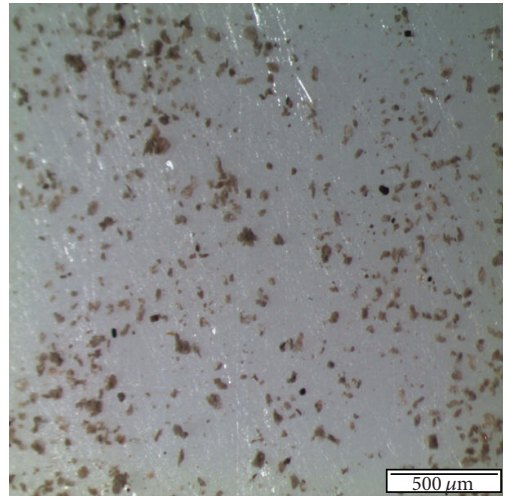

(b) $d_{\mathrm{NO}}>38 \mu \mathrm{m}$

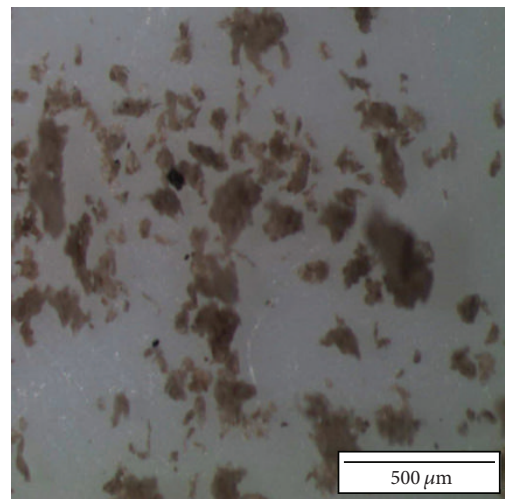

(e) $d_{\mathrm{NO}}>125 \mu \mathrm{m}$

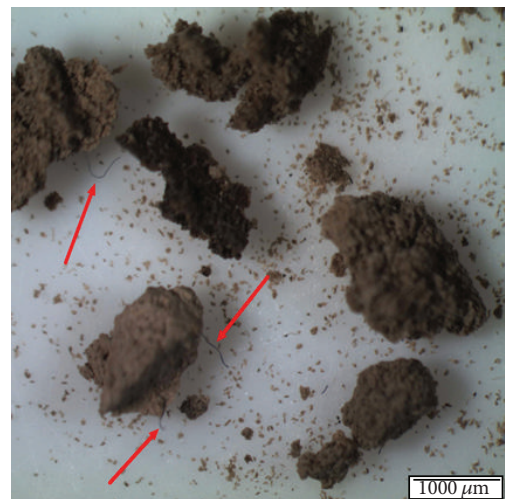

(h) $d_{\mathrm{NO}}>800 \mu \mathrm{m}$

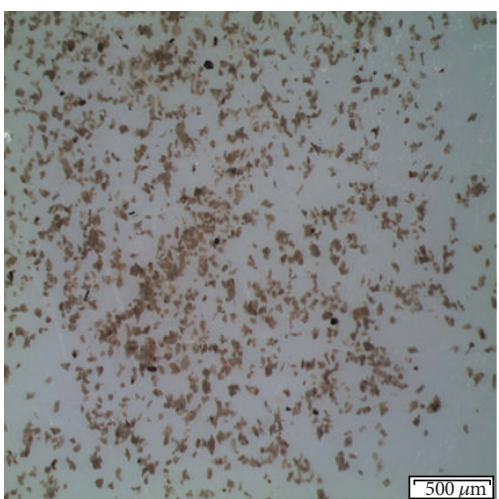

(c) $d_{\mathrm{NO}}>45 \mu \mathrm{m}$

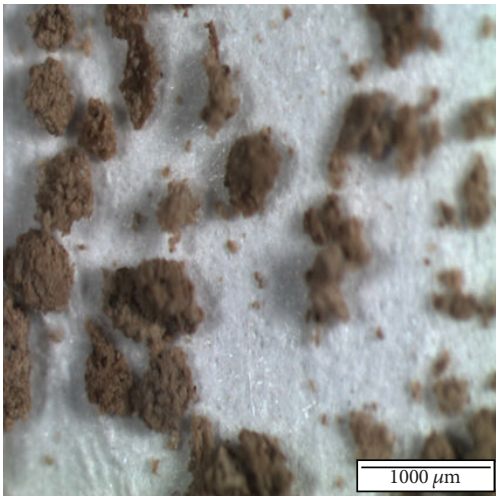

(f) $d_{\mathrm{NO}}>250 \mu \mathrm{m}$

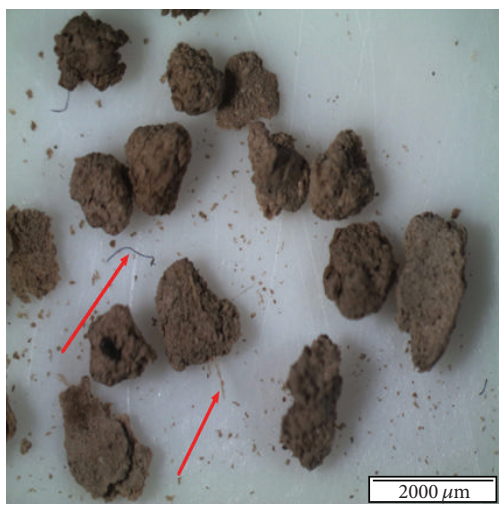

(i) $d_{\mathrm{NO}}>1000 \mu \mathrm{m}$

FIGURE 6: Images of non-oily POME sediments at different sieve opening sizes.

be retained in a particle size range of $63-125 \mu \mathrm{m}$. The AR for oily POME fibres could not be determined since it was very difficult to obtain a single fibre from oily POME samples as the particles were attached to the fibre and covering it as shown in Figure 7.

3.5. Densities of Oily and Non-Oily POME Sediments. The densities of oily and non-oily POME sediments are shown in Table 7.

It is obvious that the density of oily POME sediments decreases as the sediment size increases. This is due to the oil content percentage which increases with the POME sediments sizes as shown in Figure 9.

Oil density is $0.89 \mathrm{~g} / \mathrm{cm}^{3}$ at $27 \pm 1^{\circ} \mathrm{C}$ (room temperature), which is less than that of the POME supernatant density of $0.998 \mathrm{~g} / \mathrm{cm}^{3}$ at the same temperature. The relation between the oily POME particle size, and its density can be explained as follows: if we assume that the oily POME particles have ideal spherical shapes, then their surface areas will be augmented with increasing POME particle size and consequently the attached oil will be mounting too. But indeed the POME particles have non-spherical irregular shape as mentioned 


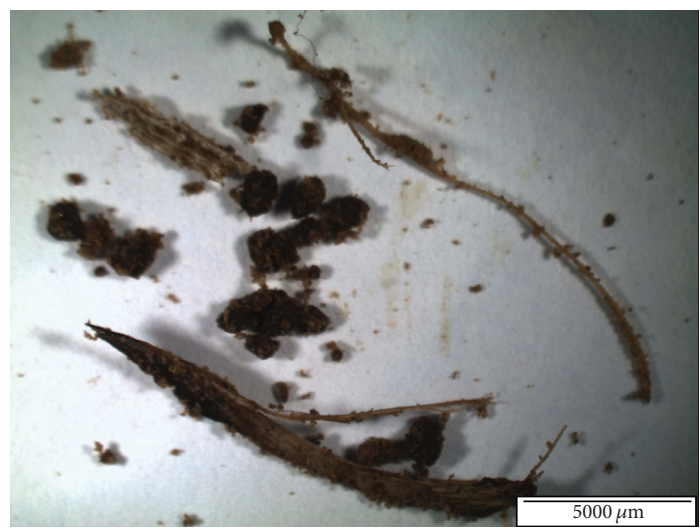

FIgure 7: Different shapes and lengths of oily POME fibres amid POME particles.

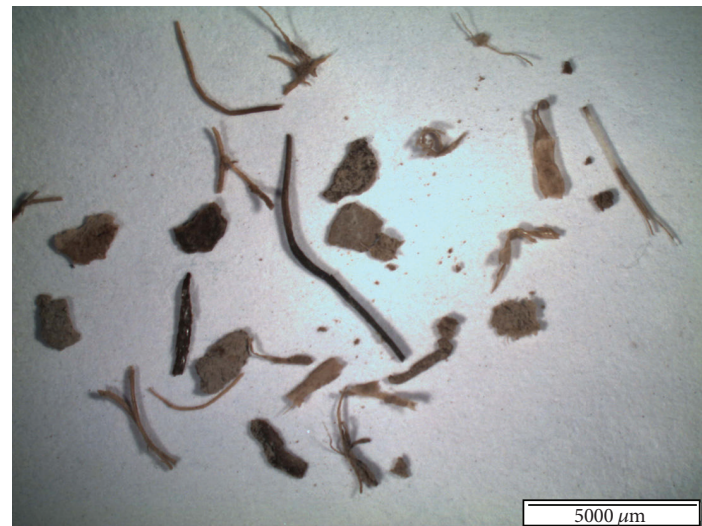

FIGURE 8: Different shapes and lengths of non-oily POME fibres.

TABLE 6: Aspect ratios of different non-oily POME fibres.

\begin{tabular}{lcc}
\hline $\begin{array}{l}\text { Longest distance } \\
(\mu \mathrm{m})\end{array}$ & $\begin{array}{c}\text { Shortest distance } \\
(\mu \mathrm{m})\end{array}$ & Aspect ratio $(\mathrm{AR})$ \\
\hline 1463.284 & 1157.411 & 1.264 \\
2133.542 & 1448.033 & 1.473 \\
2179.541 & 1188.276 & 1.834 \\
3054.830 & 350.000 & 8.728 \\
2976.777 & 108.000 & 27.563 \\
5639.450 & 200.000 & 28.197 \\
9591.940 & 250.000 & 38.368 \\
4681.750 & 100.000 & 46.818 \\
\hline
\end{tabular}

before which means that the POME particle surface area was bigger than the spherical particle. The increasing surface areas led to an increase in the amount of attached oil inside the pores and on the surface of the POME particles. This explains the reason behind the decrease in oily POME particle densities with the increase in oily POME particle size. On the other hand, the density of non-oily POME particles is increased with increasing the particles' size because there are no oil droplets to the POME particles.
TABLE 7: The densities of oily and non-oily POME sediments.

\begin{tabular}{lccc}
\hline $\begin{array}{l}\text { Sieve size } \\
\text { range }(\mu \mathrm{m})\end{array}$ & $\begin{array}{c}\text { Mean POME } \\
\text { diameter } \\
(\mu \mathrm{m})\end{array}$ & $\begin{array}{c}\text { Oily POME } \\
\text { sediments } \\
\text { density }\left(\mathrm{g} / \mathrm{cm}^{3}\right)\end{array}$ & $\begin{array}{c}\text { Non-oily POME } \\
\text { sediments } \\
\text { density }\left(\mathrm{g} / \mathrm{cm}^{3}\right)\end{array}$ \\
\hline$-45+38$ & 41.5 & - & 1.0410 \\
$-63+45$ & 54 & - & 1.0987 \\
$-125+63$ & 94 & 1.1015 & 1.1506 \\
$-250+125$ & 187.5 & 0.9860 & 1.3164 \\
$-500+250$ & 375 & 0.9750 & 1.5118 \\
$-800+500$ & 650 & 0.9480 & 1.5900 \\
$-1000+800$ & 900 & 0.9200 & 1.6041 \\
$-1400+1000$ & 1200 & 0.9150 & 1.6060 \\
\hline
\end{tabular}

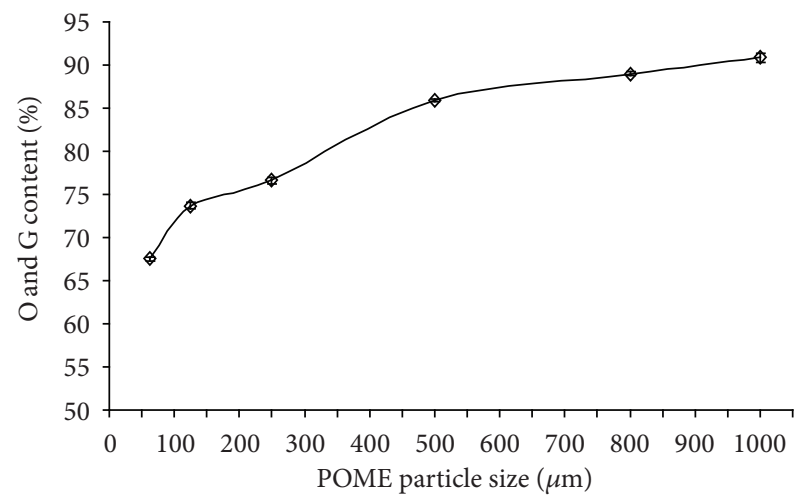

Figure 9: The relationship between the oily POME particles sizes $(\mu \mathrm{m})$ and the oil content $(\%)$.

\section{Conclusion}

The raw POME is a mixture of water, oil, and sediments (solid particles and fibres). The oil covered some of these particles and fibres and consequently affected their characteristics such as particle size distribution, particle shape, surface morphology, and their densities. The particle size of oily POME ranged between $63 \mu \mathrm{m}$ and $1000 \mu \mathrm{m}$ and the nonoily POME particles between $38 \mu \mathrm{m}$ and $1000 \mu \mathrm{m}$. The size characteristics $\left(D_{16}, D_{50}\right.$, and $\left.D_{84}\right)$ and the statistical parameters $\left(D_{g}, \sigma_{g}\right)$ are different between oily and non-oily POME particles. The POME particles have nonspherical irregular shape because of that aspect ratio (AR) and circularity as shape factors have been used to describe the degree of divergence of these natural sediments from spherical shape. The AR was found to be more relevant to POME fibres, and circularity shape factor was found to be more suitable for POME particles. The fibres found among these particles have different sizes and shapes such as simple fibre, branched fibre, and flaky fibre. For oily POME sediments, the fibres are seen among particles sized $250 \mu \mathrm{m} \leq d_{\mathrm{O}} \leq 1000 \mu \mathrm{m}$. However, these fibres can be obscured when completely covered by the particles. Non-oily POME fibres can be observed among particle sized between $500 \mu \mathrm{m}$ and $1000 \mu \mathrm{m}$. The oily POME particles have lower density than that of non-oily POME because of the adhered and embedded oil and grease within 
the particles. The oily POME sediment density was found to decrease with the increasing of size because of the increasing surface area of these particles and the increasing amount of attached oil. Conversely, the density of non-oily POME particles increased with the increasing of particle size.

\section{Acknowledgments}

The authors gratefully acknowledge the Universiti Sains Malaysia (USM) for the financial support and the research facilities of the Environmental Division of the School of Industrial Technology, USM. Special thanks go to MALPOM Industries Sdn. Bhd. for providing the sample of POME throughout this research work.

\section{References}

[1] K. Y. Foo and B. H. Hameed, "Insight into the applications of palm oil mill effluent: a renewable utilization of the industrial agricultural waste," Renewable and Sustainable Energy Reviews, vol. 14, no. 5, pp. 1445-1452, 2010.

[2] Y. S. Wong, M. O. A. B. Kadir, and T. T. Teng, "Biological kinetics evaluation of anaerobic stabilization pond treatment of palm oil mill effluent," Bioresource Technology, vol. 100, no. 21, pp. 4969-4975, 2009.

[3] S. Bhatia, Z. Othman, and A. L. Ahmad, "Coagulationflocculation process for POME treatment using Moringa oleifera seeds extract: optimization studies," Chemical Engineering Journal, vol. 133, no. 1-3, pp. 205-212, 2007.

[4] A. L. Ahmad, S. Bhatia, N. Ibrahim, and S. Sumathi, "Adsorption of residual oil from palm oil mill effluent using rubber powder," Brazilian Journal of Chemical Engineering, vol. 22, no. 3, pp. 371-379, 2005.

[5] M. B. Agustin, W. P. Sengpracha, and W. Phutdhawong, "Electrocoagulation of palm oil mill effluent," International Journal of Environmental Research and Public Health, vol. 5, no. 3, pp. 177-180, 2008.

[6] T. Y. Wu, A. W. Mohammad, J. M. Jahim, and N. Anuar, "Palm oil mill effluent (POME) treatment and bioresources recovery using ultrafiltration membrane: effect of pressure on membrane fouling," Biochemical Engineering Journal, vol. 35, no. 3, pp. 309-317, 2007.

[7] T. Allen, Powder Sampling and Particle Size Determination, Elsevier, 2003.

[8] Z. Li, J. Yang, X. Xu et al., "Particle shape characterization of fluidized catalytic cracking catalyst powders using the mean value and distribution of shape factors," Advanced Powder Technology, vol. 13, no. 3, pp. 249-263, 2002.

[9] S. Almeida-Prieto, J. Blanco-Méndez, and F. J. Otero-Espinar, "Microscopic image analysis techniques for the morphological characterization of pharmaceutical particles: influence of the software, and the factor algorithms used in the shape factor estimation," European Journal of Pharmaceutics and Biopharmaceutics, vol. 67, no. 3, pp. 766-776, 2007.

[10] R. Davies, "Size measurment," in Powder Technology: Fundamentals of Particles, Powder, Beds, and Particle Generation, $\mathrm{H}$. Masuda, K. Higashitani, and H. Yoshida, Eds., pp. 13-32, CRC Press, 2007.

[11] H. W. Bernhardt, "Shape factors of bagasse particles," in Proceedings of the South African Sugar Technologists' Association, pp. 181-184, 1993.
[12] A. M. Bouwman, J. C. Bosma, P. Vonk, J. A. Wesselingh, and H. W. Frijlink, "Which shape factor(s) best describe granules?" Powder Technology, vol. 146, no. 1-2, pp. 66-72, 2004.

[13] M. Mandø and L. Rosendahl, "On the motion of non-spherical particles at high Reynolds number," Powder Technology, vol. 202, no. 1-3, pp. 1-13, 2010.

[14] Z. Li, H. Zhai, and M. Tan, "Particle shape characterization of brown corundum powders by SEM and image analysis," in Proceedings of the International Technology and Innovation Conference (ITIC '06), pp. 1310-1313, London, UK, November 2006.

[15] R. M. Carter and Y. Yan, "Measurement of particle shape using digital imaging techniques," Journal of Physics, vol. 15, no. 1, pp. 177-182, 2005.

[16] T. Allen, Particle Size Measurment, Chapman and Hall, 1981.

[17] H. G. Brittain, "Particle-size distribution, part III: determination by analytical sieving," Pharmaceutical Technology, vol. 26, no. 12, pp. 56-64, 2002.

[18] G. Ranjan and A. S. R. Rao, Basic and Applied Soil Mechanics, New Age International Publishers, 2005.

[19] F. A. Assaad, P. E. LaMoreaux, and T. H. Hughes, Field Methods For Geologists and Hydrogeologists, Springer, 2004.

[20] E. S. Reddy, Measurement of Engineering Properties of Soils, New Age International, 2002.

[21] R. M. Gabriel, M. B. Edgar, and S. C. Rodolfo, "Physical characterizations of sands and their influence in fall velocity," American Journal of Environmental Sciences, vol. 4, no. 3, pp. 238-244, 2008.

[22] Y. Kousada and Y. Endo, "Particle Density," in Powder Technology: Fundamentals of Particles, Powder Beds, and Particle Generation, H. Masuda, K. Higashitani, and H. Yoshida, Eds., pp. 49-52, CRC Press, 2007.

[23] H. Adi, I. Larson, and P. Stewart, "Laser diffraction particle sizing of cohesive lactose powders," Powder Technology, vol. 179, no. 1-2, pp. 90-94, 2007.

[24] J. D. McKenna, J. H. Turner, and J. P. McKenna Jr., Fine Particle (2.5 Microns) Emissions: Regulations, Measurement, and Control, John Wiley \& Sons, 2008.

[25] D. L. Inman, "Measures for discribing the size distribution of sediments," Jounal of Sedimentary Research, vol. 22, no. 3, pp. 125-145, 1952.

[26] V. A. Vanoni, Sedimentation Engineering, American Society of Civil Engineers, 2006.

[27] V. S. P. Bitra, A. R. Womac, Y. T. Yang et al., "Knife mill operating factors effect on switchgrass particle size distributions," Bioresource Technology, vol. 100, no. 21, pp. 5176-5188, 2009.

[28] S. J. Blott and K. Pye, "Gradistat: a grain size distribution and statistics package for the analysis of unconsolidated sediments," Earth Surface Processes and Landforms, vol. 26, no. 11, pp. 1237-1248, 2001.

[29] J. Goldstein, D. E. Newbury, D. C. Joy, P. Echlin, C. E. Lyman, and E. Lifshin, Scanning Electron Microscopy and X-Ray Microanalysis, Springer, 2003.

[30] T. Allen, Data Presentation and Interoretation, Powder Sampling and Particle Size Determination, Elsevier, 2003.

[31] M. Li, D. Wilkinson, and K. Patchigolla, "Comparison of particle size distributions measured using different techniques," Particulate Science and Technology, vol. 23, no. 3, pp. 265-284, 2005. 
[32] A. Abouel-Kasem, "Particle size effects on slurry erosion of 5117 steels," Journal of Tribology, vol. 133, no. 1, Article ID 014502, 7 pages, 2011.

[33] G. Hawley, "Plastics," in Industrial Minerals and Their Uses: A Handbook and Formulary, P. A. Ciullo, Ed., pp. 353-398, Noyes, 1996. 

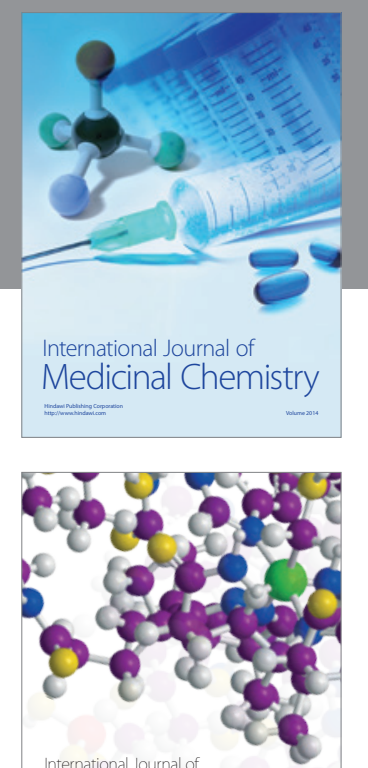

\section{Carbohydrate} Chemistry

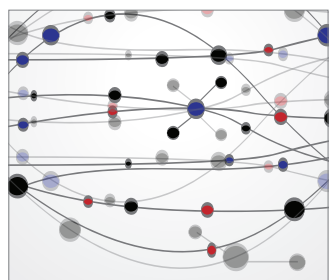

The Scientific World Journal
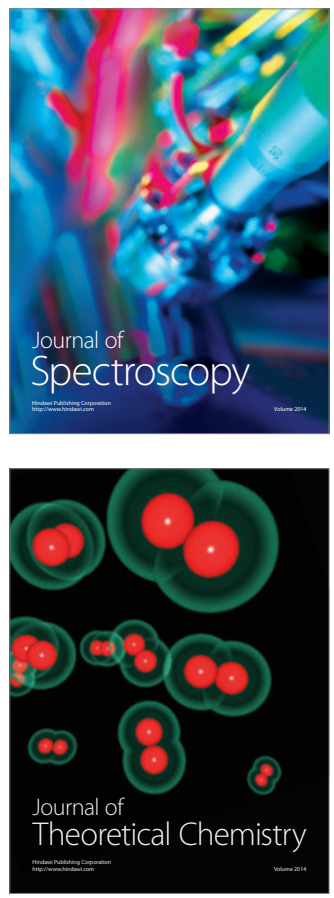
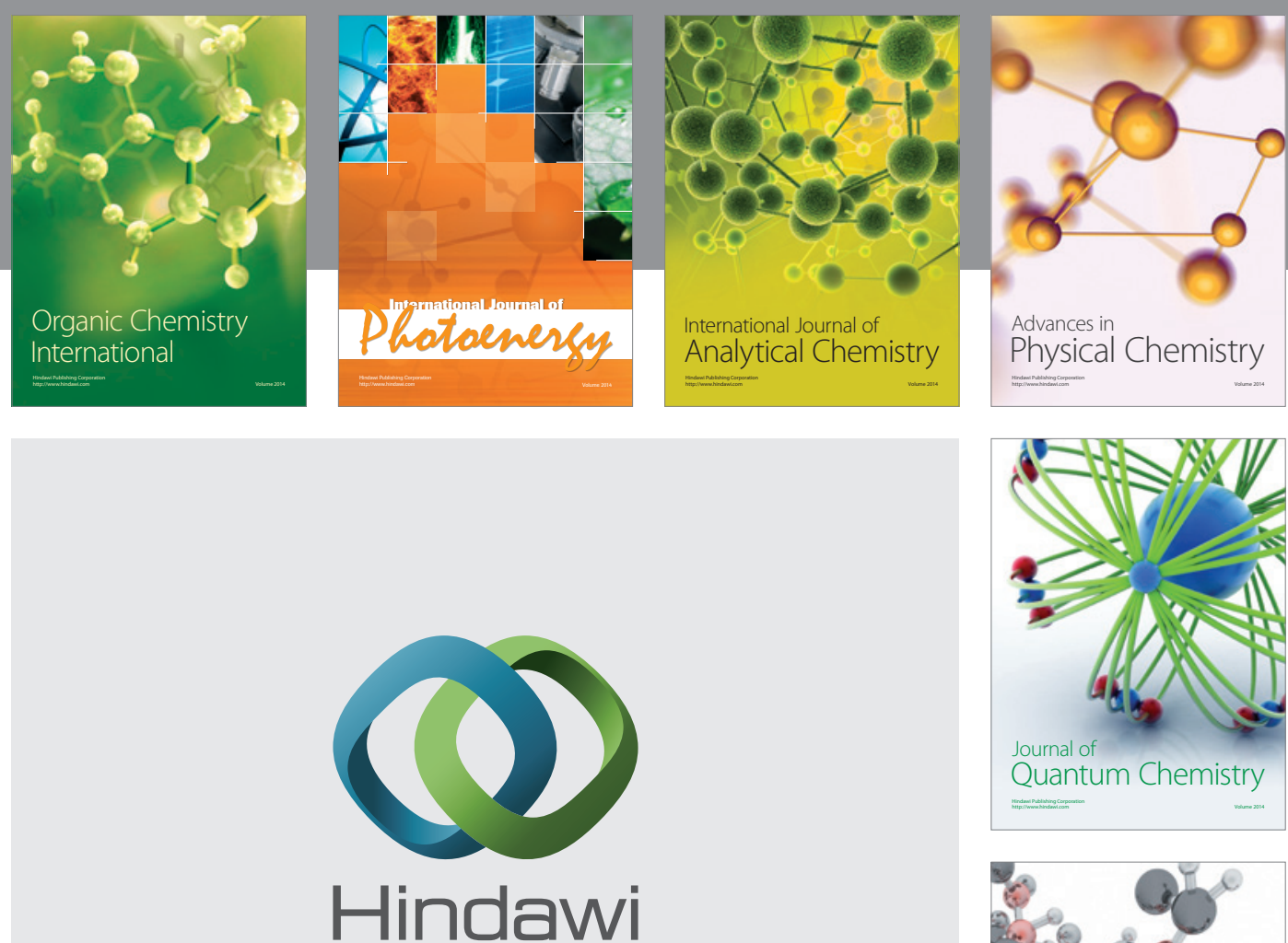

Submit your manuscripts at

http://www.hindawi.com

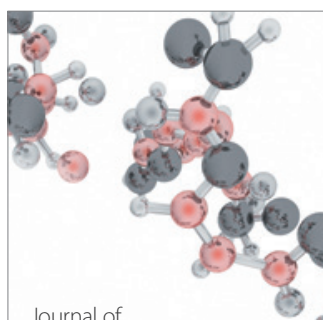

Analytical Methods

in Chemistry

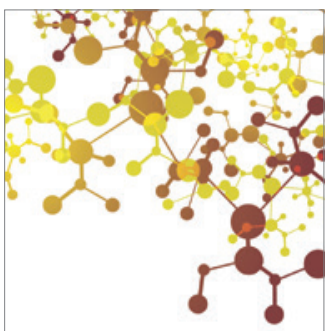

Journal of

Applied Chemistry

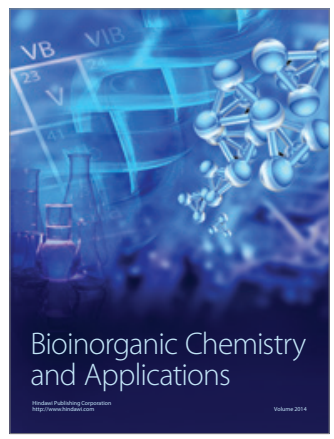

Inorganic Chemistry
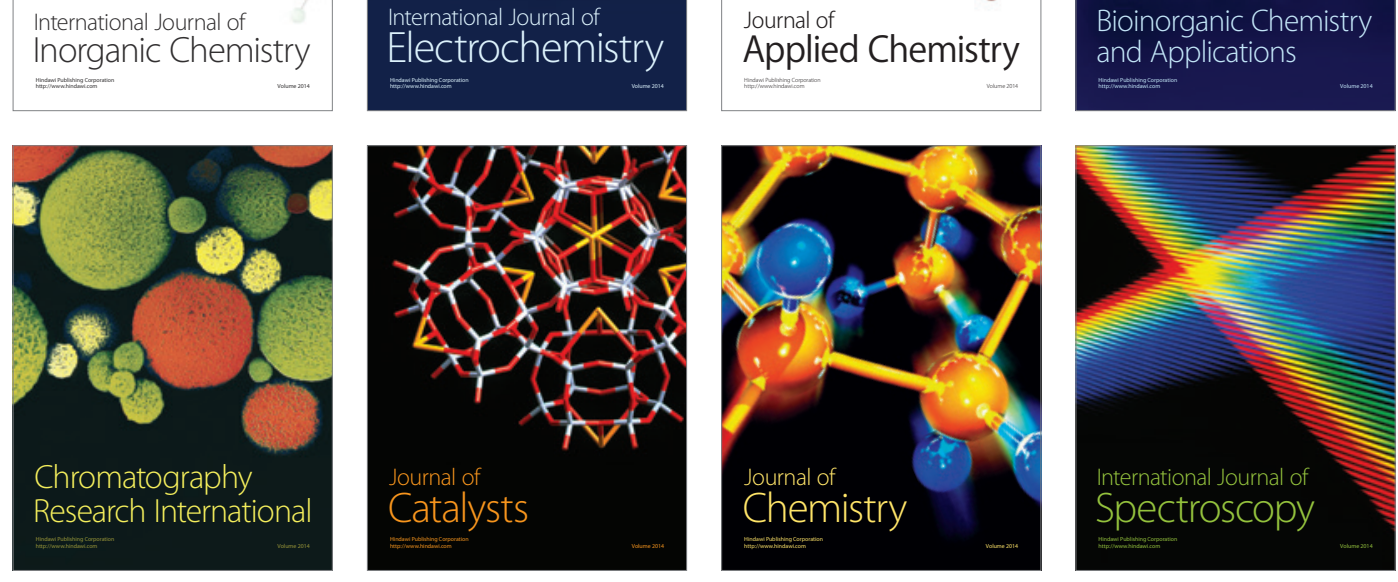